\title{
The role of universities in a network of subsidized R\&D collaboration: The case of the biotechnology-industry in Germany
}

\author{
Christoph Roesler $^{2}$ Tom Broekel ${ }^{1,2}$ (ID
}

Accepted: 30 August 2017 / Published online: 11 September 2017

(C) The Author(s) 2017. This article is an open access publication.

\begin{abstract}
This paper contributes to the growing literature on knowledge network evolution. It provides an analysis of the role universities play in a network emerging from the joint participation of organizations in $R \& D$ projects subsidized by public authorities. In addition to theorizing universities' effect on network formation processes, the paper includes an empirical study identifying the main drivers behind the formation of the subsidized network of R\&D collaboration in the German biotechnology industry.

We find that universities strongly shape the evolution of the network in the period 2007-2010. They are clearly central knowledge sources and dominate the network as partners in many $R \& D$ projects. While knowledge links among universities are an essential part of the network, universities are also able to connect local firms to inter-regional knowledge networks. Accordingly, subsidies for joint R\&D support universities in acting as regional gatekeepers and thereby facilitate local and interregional knowledge diffusion.
\end{abstract}

Keywords Collaboration networks $\cdot$ Subsidized R\&D $\cdot$ Universities · Dynamic network models $\cdot$ Biotechnology

C. Roesler

roesler@wigeo.uni-hannover.de

T. Broekel

broekel@wigeo.uni-hannover.de

1 Department of Economic Geography, Utrecht University, Utrecht, The Netherlands

2 Institute of Economic and Cultural Geography, Leibniz University of Hanover, Hanover, Germany 


\section{Introduction}

Firms' competitiveness emerges from the capability to exploit, integrate, and recombine existing knowledge in order to produce new knowledge more efficiently than their competitors (Kogut and Zander 1992; Grant 1996). Knowledge acquisition and generation are thereby increasingly the result of collaborative research and development $(\mathrm{R} \& \mathrm{D})$ activities.

Engaging in joint R\&D gives access to additional resources (Hagedoorn 2002; Powell et al. 2005a) and embeds organizations into knowledge networks granting exposure to knowledge diffusing therein (see Broekel and Graf 2012; Balland 2012; Cassi et al. 2012). In high tech industries (Hagedoorn 1993) firms particularly engage in collaboration to tap external knowledge, which is complementary to their own knowledge base.

Asheim and Gertler (2004) argue that innovation processes systematically depend on industries' knowledge bases, whereby a distinction can be made into analytical, synthetic and symbolic knowledge bases. While the synthetic knowledge bases are said to primarily consist of engineering based knowledge and the symbolic are mainly comprised of artistic and creative knowledge, the analytical knowledge base is characterized by highly codified scientific knowledge. Plum and Hassink (2011) puts forward that these differences should tend to go along with distinct knowledge network structures. It can be expected that industries building upon analytical knowledge will crucially exploit scientific knowledge inputs, which should make links to universities of vital importance (Asheim and Gertler 2004).

While some studies provide some evidence for this claim (Broekel and Boschma 2011; Plum and Hassink 2011; Graf and Henning 2009), they primarily look at snapshots of knowledge networks at one moment in time. Consequently, we still know little about if and how universities contribute to the evolution of knowledge networks within industries based on analytical knowledge bases. More precisely, it is still unclear if universities contribute more strongly to the development of knowledge networks in these types of industries than other types of organizations. In addition, due to scientific knowledge's high degree of codification, geographic proximity can be hypothesized to be less likely a restricting factor for R\&D collaboration than for industries in other knowledge bases (Asheim and Coenen 2005; Plum and Hassink 2011). It is the paper's primary aim to empirically address these questions by using the biotechnology industry as an example of an analytical knowledge base (Cockburn and Henderson 1997; Toole 2012). This industry's knowledge networks have been intensively studied in the past (Powell et al. 1996b, 2005b; Owen-Smith et al. 2002). They have also been investigated regarding the specificities of industry-university linkages (Owen-Smith et al. 2002). However, these studies primarily relied on graphical interpretation or bivariate correlations. In contrast, the present study utilizes current methods of dynamic network analysis allowing for more comprehensive insights.

In addition, we focus on a very specific type of network, namely a knowledge network emerging from the subsidization of joint $R \& D$ projects. Networks emerging from the subsidization of joint $\mathrm{R} \& \mathrm{D}$ projects have received some attention in the literature (Scherngell and Barber 2009; Broekel and Graf 2012). It has been shown 
that the evolution of such networks is driven by similar factors as the development of knowledge networks, which are not based on subsidization. In particular, different types of proximities (geographic, cognitive, social, institutional, organizational) and network structural factors (triadic closure, preferential attachment) foster the formation of knowledge links in such networks, i. e. the participation in subsidized joint $\mathrm{R} \& \mathrm{D}$ projects. However, the majority of existing studies concentrate on industries with synthetic knowledge bases (see Balland 2012; Buchmann and Pyka 2014). It is the second objective of the paper to study the evolution of a network emerging from the subsidization of joint $\mathrm{R} \& \mathrm{D}$ projects within the context of an analytical knowledge base, which has rarely been done in the past.

Our results indicate that the nature of biotechnology's knowledge bases matters for the evolution of its network of subsidized R\&D collaboration. The network's evolution shares some characteristics with other types of knowledge networks. For instance, preferential attachment and cognitive proximity explain significant portions of new link formation. However, we also identify a number of peculiarities in the development of the network, which relate to the industry's analytical knowledge base. Universities are clearly found to be central players in the network. Institutional boundaries are frequently crossed in university-firm collaboration and are vital for interactive learning in this industry. In contrast, geographic distance is found to stimulate collaboration, as organizations need to access specific knowledge sources, which tend to be located at greater distances.

The paper is structured as follows. In the first section, we briefly outline the importance of universities in terms of knowledge production and diffusion. We then discuss general network drivers and outline how they are potentially influenced by policy programs, as well as by the presence of universities. Following this, we present an empirical study on the evolution of a network of subsidized joint R\&D in the German biotechnology industry. In the empirical approach, we make use of Stochastic Actor Oriented Models, which are briefly introduced. In the following section, we present the empirical findings. The paper closes with a conclusion that summarizes the results and makes some suggestions for future research.

\section{Universities, subsidies, and knowledge networks}

Universities engage in a wide range of activities. First and foremost, they educate students and thereby upgrade human capital. Equally important is the role of universities as knowledge accumulators and generators (Blind and Grupp 1999; Mansfield and Lee 1996). ${ }^{1}$ While universities have traditionally been centers of basic research (mode 1), they increasingly engage in the cooperative conduction of applied research (mode 2) as well (Gibbons 1994). Crucially, significant parts of their output are codified, implying that it can be relatively easily transferred over large geographic distances.

However, their importance for industries' $R \& D$ activities differs depending on the underlying knowledge base. Asheim and Gertler (2004) distinguish between

\footnotetext{
${ }^{1}$ Universities offer a wide range of other services as incubators, consultants, and producers, etc.
} 
analytical, synthetic and symbolic knowledge bases. The synthetic knowledge base strongly builds on engineering based knowledge while innovation processes in the symbolic base primarily utilize artistic and creative knowledge. Scientific knowledge is of crucial importance in the analytical knowledge base. R\&D activities in the biotechnology industry clearly belong to the analytical type, which makes universities important knowledge sources (Asheim and Gertler 2004, Plum and Hassink 2011, Broekel and Boschma 2011).

Most German universities are publicly financed and their set-up can therefore be seen as an R\&D policy tool. For instance, in hope of universities' positive contribution to regional technological capabilities and knowledge creation, many of them have purposefully been set up in regions lacking these capabilities (Beise and Stahl 1999). Universities are argued to emit knowledge spillovers through the teaching of students, who "transport" their knowledge to the private sector by entering their professional careers at other organizations. Other knowledge spillover mechanisms are university spin-offs, licensing, and shared laboratories. ${ }^{2}$ In the following, we focus on yet another transmission channel that is gaining more and more importance: knowledge spillovers emerging from the participation in subsidized joint $\mathrm{R} \& \mathrm{D}$ projects.

Due to their up-to-date $R \& D$ activities and access to international collaboration partners, universities generate and accumulate valuable knowledge assets making them attractive collaboration partners (Jaffe 1989; Blind and Grupp 1999). In addition, universities have a non-profit incentive structure making them less likely to free-ride on partners' efforts, which frequently troubles firm-firm collaboration (Kesteloot and Veugelers 1995). Nevertheless, collaboration between firms and universities is still perceived of to be below a social optimum. To enhance the diffusion of academic knowledge and make greater use of it, policy increasingly tries to support collaborative activities between universities and the private sector (Beise and Stahl 1999).

One way of achieving this is to provide monetary incentives for universities and firms to collaborate. Frequently, such incentives take the form of subsidies for joint R\&D projects. The EU-Framework Programs are a prominent example of such a policy (Breschi and Cusmano 2004). In this case, all projects subsidized through this program are joint projects with universities being among the largest group of beneficiaries. In accordance, the German federal government is also steadily increasing the share of subsidies for joint R\&D projects (Broekel and Hartog 2013a). By stimulating the collaboration between universities and other organizations, public policy interrelates two types of $R \& D$ policies: the provision of $R \& D$ capacities (universities and R\&D subsidies) and the facilitation of inter-organizational collaboration (support for joint projects). Hence, policy does not only impact knowledge creation but also inter-organizational knowledge diffusion. While the first has received considerable attention in the literature (see, e.g. Camagni 1991; Fritsch and Slavtchev 2007), the role universities play in networks emerging from the subsidization of joint $R \& D$ projects has received far less attention.

\footnotetext{
2 Note that universities may also be the recipients of knowledge spillover from the private sector.
} 
Insights about this will not only contribute to the understanding of how policy activities translate into knowledge network development but will also add to the understanding of interrelating policy effects.

The evolution of knowledge networks in general is driven by factors at three distinct levels: the actor, the dyad and the structural network level (Broekel and Hartog 2013b). In the following we will discuss in more detail for each of these levels, what factors drive knowledge network evolution and what role universities may play in this context.

\subsection{Universities as network nodes}

On the actor level, actors and their attributes are made central parameters in explaining the sustenance, evolution or dissolution of a collaboration. In their study about factors leading to R\&D projects between universities and industries, Fontana et al. (2006) show that the absolute size of an industrial partner has a positive effect on the probability to establish a tie. This is related to the pool of resources which is expected to increase with the size of an organization. As the establishment of and subsequently the participation in $\mathrm{R} \& \mathrm{D}$ projects is time and cost intensive, larger organizations have the capacity to deal with these factors (Marin and Siotis 2008). While universities are rather large, the entities that actually engage in subsidized $\mathrm{R} \& \mathrm{D}$ projects are institutes and departments. While these may appear to be relatively small compared to firms, they are characterized by high absorptive capacities allowing for engagement in a greater number of simultaneous collaborations.

Powell et al. (1996a) propose that prior collaboration experience of organizations might positively influence their will to take part in R\&D projects. Former experience helps organizations to choose future collaboration partners and also lowers costs and efforts of establishing and running potential R\&D projects (Levitt and March 1988; Fritsch and Lukas 2001). These advantages occur because certain procedures are already built in as routines through prior experience. This is clearly related to the organization's age, as older organizations have a longer 'life span' to establish and learn from collaborations. With universities having a much longer history in biotechnology research than most firms, they can also build upon richer R\&D and collaboration experiences.

In addition to these points, we highlighted above that universities are characterized by R\&D and collaboration friendly incentive structures, which make them very active collaborators. The value of their up-to-date knowledge adds to their attractiveness as collaboration partners. Accordingly, we expect universities to be highly central actors in the studied network of subsidized R\&D collaboration. Such a role may also be played by extramural R\&D institutes such as those of the Max-PlanckSociety or Fraunhofer Association. However, these organizations tend to be more specialized than universities, which makes their parallel participation in many (subsidized) R\&D projects less likely. Moreover, they also tend to collaborate less with private companies. Beise and Stahl (1999) report that when private firms collaborate with extramural research organizations, these usually belong to the Fraunhofer Association with its strong application-oriented focus. Institutes of the other large public research organizations (Max-Planck Society, Helmholtz-Society, Leibniz As- 
sociation) rarely engage with private firms. Accordingly, we expect universities to play a more prominent role as network actors than extra-mural research organizations. An exception being the seven institutes of the Fraunhofer Association active in biotechnology.

\subsection{Universities as link partners}

Network theory shows that in addition to nodes' individual attributes, their relational characteristics are similarly important for explaining the evolution of networks. Crucially, actors' mutual similarity influences the probability of a link being formed or dissolved between them. Lazarsfeld and Merton (1954) introduced the term 'homophily effect' to capture the tendency of actors to connect with actors who have similar attributes. This concept can be linked to the concept of proximity in economic geography. In a nutshell, the proximity concept states that proximities in broader dimensions can help to foster innovative activities and interactive learning. Building on the ideas of the French School of Proximity Dynamics, Boschma (2005) developed a concept of five different proximities which should be considered to understand and explain interactive learning and innovation. Next to geographical proximity, Boschma (2005) argues, cognitive, organizational, social as well as institutional proximity are important factors which are needed to explain knowledge creation.

The first is cognitive proximity, which refers to the degree of overlap in two actors' knowledge bases. Actors need to have a complementary absorptive capacity to identify, interpret, and exploit the knowledge of others (Cohen and Levinthal 1990). Hence, overlap in actors' knowledge bases is essential for efficient communication. Proximity in the institutional dimension is supposed to have a positive influence on the collaborative activity between organizations of the same institutional type. It is assumed that organizations, which belong to the same institutional entity, share similar routines. These routines could comprise of similar research procedures, research standards or the execution of $R \& D$ projects. These organizations might also share similar administrative structures, which allow for easier knowledge exchange and collaboration. Organizational proximity can be thought of the degree to which organizations share the same formal and informal institutions. It is supposed to positively influence the cooperation probability of organizations belonging to the same parent organization. Social proximity in terms of collaboration can be interpreted as learning effects emerging through repetitive cooperation between the same set of organizations. For instance, Zollo et al. (2002) show that partner-specific experience enhances the collaboration performance due to the development of inter-firm coordination and respective organizational routines. Lastly, geographical proximity enhances collaboration probability as well. Following Feldman and Florida (1994), geographical proximity makes face-to-face contact easier and therefore more likely. Face-to-face contacts are supposed to enhance interactions in general and the exchange of tacit knowledge in particular.

How do these proximities relate to subsidized R\&D collaboration and the role of universities therein? Organizations are subject to different institutional frameworks. For instance, while universities are designed and encouraged to share knowledge, 
firms have to be more careful when sharing knowledge assets in order to avoid losing their competitive advantage. In addition, firms need to act profit-oriented, which is not the case for universities. These institutional differences are likely to reduce collaboration activities between the two spheres in general (Broekel and Boschma 2012). However, many policy subsidization programs are designed to stimulate university — private collaboration in order to facilitate knowledge diffusion from the public to the private sector.

Hence, in subsidized R\&D collaboration networks strong monetary incentives may exist for overcoming institutional boundaries, which otherwise lowers collaboration probabilities. Accordingly, institutional proximity is expected to play a minor role in subsidized R\&D networks, which are likely to be characterized by a larger share of university-firm linkages. This may strongly differ between industries, as basic research (which tends to be conducted at universities) varies in importance between industries (see for a discussion and empirical analysis on this matter Broekel and Graf 2012).

For the same reason, it might be that cognitive distance will be of less relevance in subsidized R\&D networks. If subsidies drive firms and universities to collaborate more frequently than in non-subsidized networks, it will also mean than cognitive proximity will be of smaller relevance. Universities tend to be at great cognitive distances to firms due to their stronger focus on basic research, which overlaps only partly with the knowledge of application-oriented R\&D activities of firms (Broekel and Boschma 2011). Accordingly, we expect to find cognitive proximity to be less relevant in networks of subsidized R\&D networks. However, some subsidization programs restrict the group of applicants to specific industries or technologies (e. g. Key technology funding in Germany). By default, these programs support joint projects of organizations with similar technological backgrounds. If such programs dominate the knowledge network, the role of cognitive proximity may be artificially increased. However, there are also programs designed to support inter-disciplinary research and collaboration. For instance, the German "ELSA-GEN" initiative promotes collaboration between different disciplines such as medicine and biology with other fields like law, social and the political science. The aim of this initiative is to reflect upon potential issues emerging from genome research and resulting effects on society and economics. Such initiatives will reduce the effect of cognitive proximity. Therefore, it is difficult to make predictions about the role of cognitive proximity in this context.

Geographic proximity is generally said to increase the likelihood of collaboration (Boschma 2005). Moreover, if knowledge networks are strongly oriented towards universities, this is likely to reinforce this effect because they frequently represent the core of formal and informal regional networks (Soete et al. 2002). Amongst others, universities have been frequently set-up to support regional economies or deliberately follow a strategy of supporting regional development. However, this effect is considerably stronger for technical colleges, which are known to be stronger oriented towards their regions' economies than universities (Beise and Stahl 1999).

It becomes clear that in networks emerging from the subsidization of joint R\&D projects, network evolution is driven by similar factors as unsubsidized networks. However, some difference can be expected and a number of these relate the 
role universities play. To explore the relevance of these factors as well as the role of universities for the evolution of subsidized networks, we analyse a network of publicly supported R\&D collaboration in the German biotechnology industry. The important role of public funding and collaboration makes the biotechnology industry in Germany an auspicious case for such an endeavour.

\section{Stochastic actor-based model}

This section provides a very brief introduction to Stochastic Actor-Based Models (SOAM). A more extensive introduction can be found in Snijders et al. (2010) and Broekel et al. (2014). Since the paper explores an undirected network, we will limit the explanation to such networks.

In general, the network data for SOAM should consist at least of two observations of a social network capturing the network at different moments in time. The network consists of a given set of actors (nodes) and their relations (ties). Attributes belonging to the individual actor (organization) are called actor covariates. In the case of organizations, these variables may be constant (e. g. year of foundation, location, institutional form) or may be changing over time (e. g. number of employees, profits, numbers of $R \& D$ projects participating). Attributes describing the relation between two actors are called dyadic covariates. Dyadic covariates might also be constant, e. g. describing the spatial distance between two organizations, or might be changing like both organizations' number of shared cooperation partners. Crucially, actor and dyadic covariates are centred around their empirical average to reduce estimation difficulties caused by collinearity (Steglich et al. 2010). In addition to these covariates, SOAM allow for the inclusion of a wide range of structural network effects.

Structural network effects show in the structure of collaboration networks as a whole influencing the probability of actors to collaborate and consequently to drive networks' development. In contrast to other studies investigating the evolution of networks (see, e.g., Ter Wal 2013; Broekel and Hartog 2013b; Balland 2012), network structural factors are of less interest in the current paper and will primarily serve as control variables. We therefore refrain from lengthy discussion and briefly present the two most important effects that will also be considered in the later empirical study.

The first structural network factor, which is frequently argued to drive the evolution, is preferential attachment (PREF.ATTACH). Barab'asi and Albert (1999) proposed that new actors in networks have the tendency to attach themselves to the actor with the highest degree centrality. Moreover, the already well-connected actors establish further links fuelling a self-reinforcing effect. Under the assumption that all new actors only attach to existing ones, a so-called power law distribution of nodes' degrees may arise. Barab'asi and Albert (1999) coined the term scale free networks. The preferential attachment effect (PREF.ATTACH) captures the tendency that organizations connect to organizations with the highest number of direct connections in the network. It is defined by the sum of the square roots of the degree of the other actors to whom an actor is linked (Ripley et al. 2011). It is given by 


$$
S_{2 i}(x)=\sum_{j} x_{i j} * \sqrt{\sum_{h} x_{h j}}
$$

whereby $i$ is the focal actor. $j$ represents $i$ 's and $h j$ 's collaboration partners. According to Ripley et al. (2011) squaring the effect yields better results. A detailed explanation of all three effects can be found in Snijders et al. (2010). ${ }^{3}$

Second, it is always recommended to include a density effect (DEGREE.DENS), which is defined as

$$
S_{l i}(x)=\sum_{j} x_{i j}
$$

and captures the general propensity of actors $i$ and $j$ to link in the specific network. Being a basic effect, it is automatically considered in all SIENA models (Ripley et al. 2011). DEGREE.DENS expresses the observed density in the R\&D collaboration network and indicates the overall tendency of organizations to form or dissolve ties. In the context of $\mathrm{R} \& \mathrm{D}$ collaboration networks, the effect can be regarded as the balance between benefits and costs of an additional collaboration. The factors will likely obtain a negative coefficient, as networks established by social processes tend to be less dense than simulated networks due to the presence of significant costs of interaction (Varas 2007). In SOAM, the simulation and estimation of networks' evolution is realized by the combination of random utility models, continuous time Markov models, and simulations (Van de Bunt and Groenewegen 2007). The central assumption of SOAM is that a network's evolution is the result of rational actions by individual actors, which seek to maximize the utility they gain from the network under some set restrictions. In other words, actors can evaluate the utility of the creation or the suspension of relations based on their own perception. The probability of a tie change is further determined by exogenous factors-on the individual and dyadic level as well as endogenous factors at the network structural level.

In contrast to other stochastic models using estimation methods such as maximum likelihood, the actor based model is carried out through the method of moments implemented by computer simulations of the network change process proposed by Snijders (1996, 2001). This method is useful for network data characterized by few observations over time. In the method of moments, the first observed network is used as a starting point, which is not modelled but sets the conditions for the following estimations. SOAM estimates model parameters by simulating the evolution from a network in $t$ to its structure in $t+1$. That means that all estimations are dependent on the first observation of a network. By repeating the simulation for a defined

\footnotetext{
3 Triadic closure or transitivity is a frequently observed tendency in social networks. According to Boschma and Frenken (2010, p. 9) the transitivity effect can be described as "[t]he probability of two forming a relation who already relate to a common third is expected to be much higher than the probability of two actors forming a relation who do not relate to a common third". While this effect represents one of the main drivers of social network evolution, we refrain from including it in the present paper. The reason is that we will work with networks constructed from subsidized joint projects implying an artificially high number of cliques (fully connected network parts), which will lead to a biased transitivity parameter (Balland 2012).
} 
number of "runs" the method of moments algorithm estimates the parameters by comparing the observed network with hypothetical networks generated by the simulations. The estimated parameters are those approximating the observed network best. Notably, the parameter estimates can be directly interpreted as how the logodds of link formation change with one unit change in the corresponding factor.

\section{Empirical data}

\subsection{The German biotechnology industry}

Aiming at the expansion of knowledge creation and the innovation potential of domestic organizations, the German government employed various policy instruments and strategies. Facing increasing competition on a global scale "[...] financial aid for $R \& D$ and innovation activities in firms and research institutions, support of cooperation, networking and cluster formation, funding of technology-oriented startups, as well as institutional support for research institutions and knowledge transfer facilities" (BMBF 2006) became popular measures of policy makers to enhance organizational innovation capacity.

The biotechnology industry has been particularly strongly supported by the German government since the late 1990s, as it is assumed to be one of the key industries of the future (see for a more detailed description of the industry's development in Germany in Fornahl et al., 2011). Fig. 1 elucidates that the number of joint R\&D projects subsidized in the biotechnology industry substantially increased since the late 1990s with a peak in the period from 2007 to 2010.

Today biotechnology contributes to various fields such as public health, waste management, environmental protection and agriculture and is an important contributor to national and international economies. To cope with the comparatively less developed national biotechnology industry in the beginning of the 1990s, the governmental assistance program BioRegio was introduced in 1995 and it is assumed to have made an important contribution to the increasing growth rate of the biotechnology industry (Dohse 2000). The main aim was to develop biotechnological capacities by connecting relevant actors and supporting newcomers to foster the innovation processes and consequently achieve increasing competitiveness in the biotechnology industry. In the first phase of the competition, three regions (BioRegion Munich, BioRegio Rheinland, BioRegio Heidelberg) were supported with 90 million Euros for the time span between 1997 and 2005. Analyses have shown that these regions, compared to others, had higher average founding rates within the biotechnology industry (Staehler et al. 2007).

Moreover, the program enhanced cooperation activities between organizations not only in the subsidized regions but also on an inter-regional scale. The authors conclude that the BioRegio and the follow up BioProfil program where important measures that helped to develop a competitive biotechnology industry in Germany.

Consequently, the German biotechnology industry presents an ideal case for studying the evolution of knowledge networks in general and that of subsidized R\&D networks in particular. Furthermore, its R\&D activities are still dominated by 


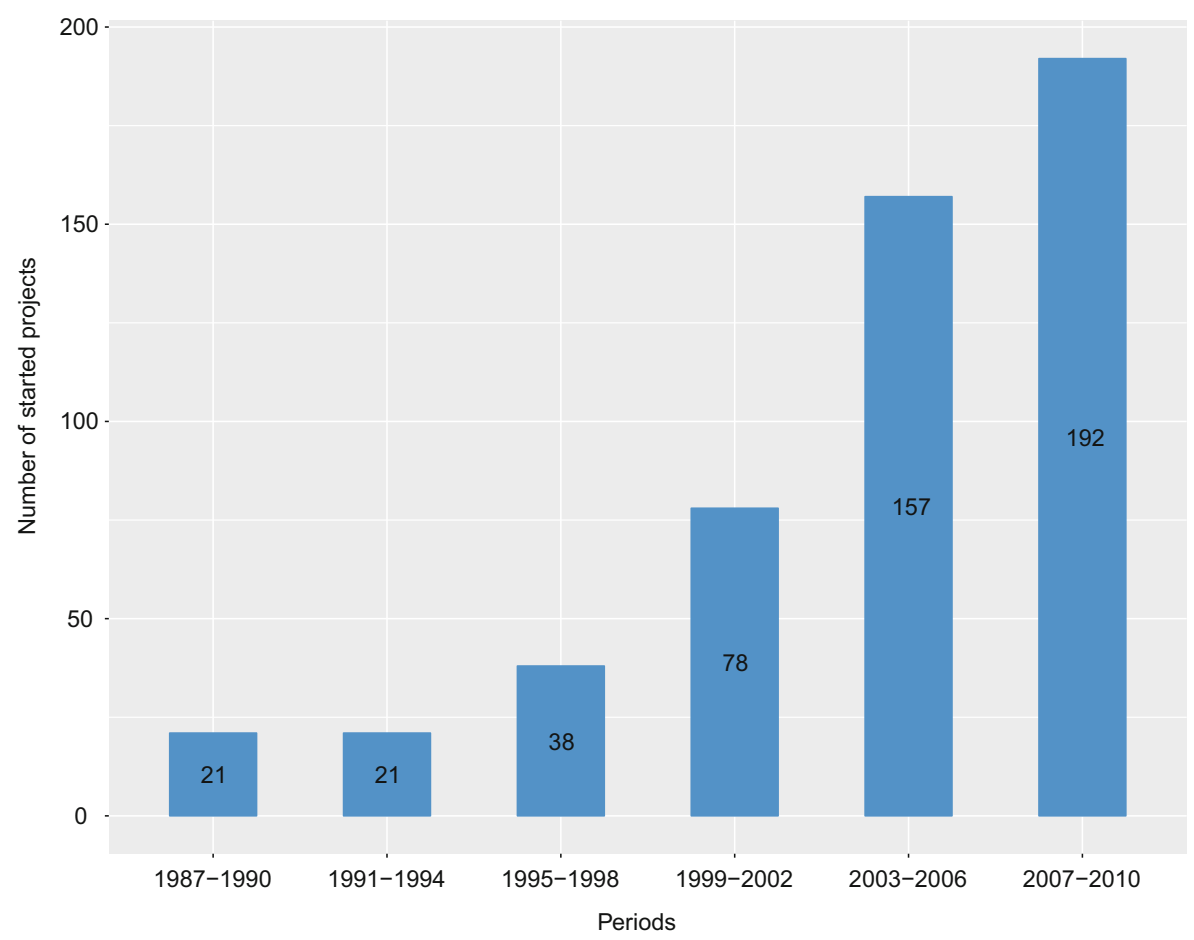

Fig. 1 Number of initiated subsidized joint R\&D projects per 4 year period (Authors' calculation utilizing the German subsidy catalogue ("Förderkatalog"))

basic science implying that universities represent central knowledge sources and key collaboration partners (Powell et al. 1996a; Niosi and Banik 2005; Meyer-Krahmer and Schmoch 1998). Moreover, universities with laboratories and teaching medical centres are frequently integral to therapeutic innovation by serving as bridges between research and new applications of pharmaceutical products. In particular, socalled bench-to-bedside or translational medicine stimulates the linking of universities' and firms' applied research.

\subsection{Data source and network construction}

To construct the network of subsidized R\&D collaboration for this industry, we rely on information from the German subsidy catalogue ("Förderkatalog"). The catalogue contains organizations and projects subsidized by the Federal Ministry of Education and Research (BMBF), Federal Ministry for Economic Affairs (BMWi), Federal Ministry for Environment, Nature Conservation and Nuclear Safety (BMU), Federal Ministry of Transport, Building and Urban Development (BMVBS) as well as the Federal Ministry of Food, Agriculture and Consumer Protection. The database contains more than 160,000 running or already finished R\&D projects subsidized by these ministries in the time span between 1960 and 2016. Information comprises the subsidized organizations, the amount of money the organization received, locations, 
industrial classification code (NACE), who jointly participated in which projects, as well as project duration. The information on participants in the joint R\&D projects are used for the construction of the network (Broekel and Graf 2012). Due to uncertainty and potential risks, the level of organizations' engagement in joint knowledge production processes are assumed be below a socially optimal level. For this reason, policy encourages collaborative research activities by means of subsidizing joint R\&D projects, which make inter-organizational collaboration obligatory for receiving subsidies (see, e.g., Scherngell and Barber 2009, 2011). Due to regulations organizations agree to when being awarded a joint R\&D grant, knowledge exchange becomes highly likely, implying that participation in subsidized R\&D projects can be interpreted as links in inter-organizational knowledge networks (see for a discussion Broekel and Graf 2012).

Additional information were obtained through the web presentation biotechnologie.de, which is initiated by the BMBF. This includes information on organizations' founding years, their numbers of employees, and specifications of research.

We collect information for all organizations belonging to the funding area and funding priorities ("Förderkatalog"/"Förderschwerpunkt") biotechnology (B) in the Federal Government's R\&D planning system ("Leistungsplansystematik") between 01.01.2007 and 31.12.2010. We consider only projects with at least two partners to reduce effects related to organizations' general capability and willingness to collaborate. Hence, our network of subsidized R\&D collaboration includes all organizations that participated in at least one joint $\mathrm{R} \& \mathrm{D}$ project classified into the funding priority area $\mathbf{B}$ in the respective time period. Links between organizations are established when two organizations jointly participate in the same project.

Fig. 2 shows the spatial distribution of subsidized joint R\&D projects at the level of districts. Intensive R\&D collaboration activities exist in the area surrounding $\mathrm{Mu}-$ nich, Mannheim, and Heidelberg. Both regions were participants in the first round of the BioRegio competition mentioned above. The same is true for the area of Berlin and Potsdam, which belong to the receiving regions of the BioProfil program and show intense R\&D project participation between 2007 and 2010. All three regions are characterized by a high number of biotechnology firms and universities as well as public research institutes. Moreover, the regions around Cologne, Aachen, Düsseldorf, Hamburg, and Hanover show increases in funding for joint R\&D projects. Notably, all their universities are significantly involved in life science and applied biotechnology. The findings on the spatial distribution of funding are in line with other findings about the general distribution of important German biotechnology regions and organizations (see Zeller 2001; Ter Wal 2013).

The data distinguishes between the name of the recipient organization and the name of the executing organization. In most instances, both names are identical. However, in case of large firms or research institutes with various sub branches located in different regions, the recipient and executing entity may vary. To keep the level of observation equal for all organizations and to control for potential "headquarter effects", we apply the approach introduced by Broekel and Graf (2012). Hereby each organization is identified by the combination of the recipient's name and the official municipality identification number of the district it is located in. 
Fig. 2 Distribution of funded joint R\&D projects within the biotechnology across German districts (Authors' calculation utilizing the German subsidy catalogue ("Förderkatalog"))

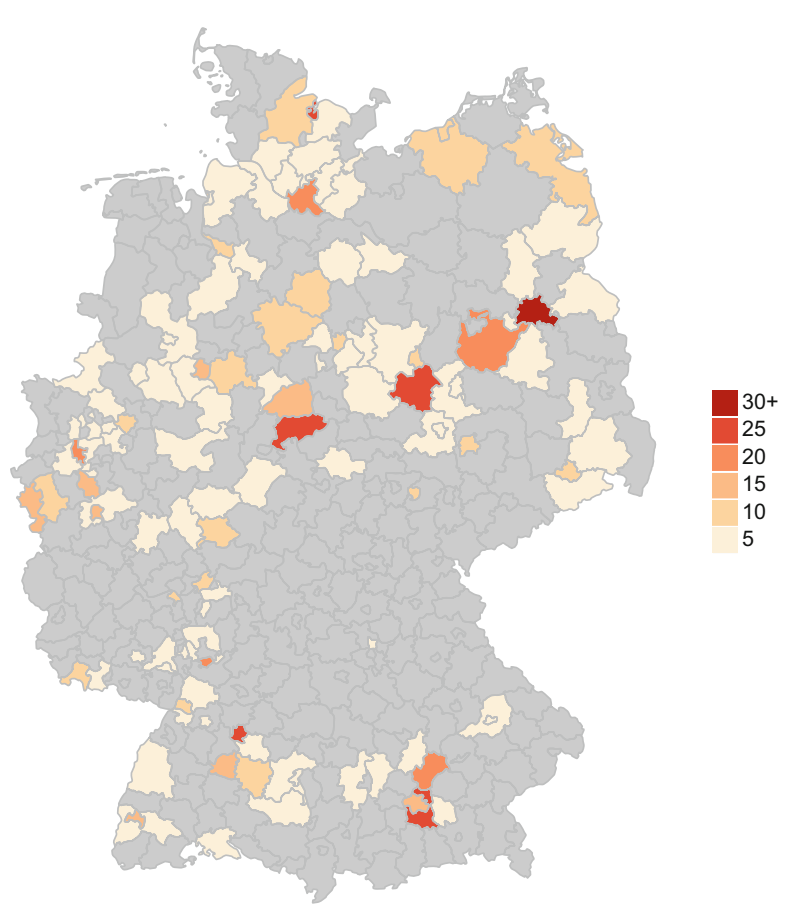

Collaborations are defined by simultaneous participation in joint R\&D projects at different points in time.

The final dataset consists of 316 unique German biotechnology organizations, which participated in at least one of 193 projects between 2007 and 2010. The average number of participants per project is 3.6 (ranging from 2 to 39). The network is constructed by projecting the two-mode network connecting all unique organizations with their joint R\&D projects into a one-mode network consisting only of organizations and their direct relation. Organizations participating simultaneously in multiple projects may (indirectly) connect to other organizations that do not interact directly in a subsidized joint project. It is argued that through contracts and regulations all participants of a project are prompted to share relevant knowledge (see for a discussion Broekel and Graf 2012). Consequently, links between actors are undirected and represent mutual agreements on a collaboration project $x i j=x j i$. For each year $(t)$ between 2007 and 2010, we construct a network matrix BTij(t) with values between $x i j=1$ and $x i j=0$ indicating an existing and non-existing link between actor $i$ and $j$ (dichotomized network), respectively.

Table 1 shows the general growth of the analysed network while. Table 2 shows the increasing density and average degree of the network for the respective years.

Fig. 3 depicts the overall share of links between the different organizational types. Links spanning institutional borders are less frequent compared to those within the same institutional framework. In particular, over one third of all links are among universities. The second largest share are links among firms (economy). The high share of links among universities underlines biotechnology's strong orientation to- 
Table 1 Network development

\begin{tabular}{lllll}
\hline Periods & $0 \rightarrow 0$ & $0 \rightarrow 1$ & $1 \rightarrow 0$ & $1 \rightarrow 1$ \\
\hline $2007-2008$ & 49,333 & 250 & 0 & 187 \\
$2008-2009$ & 49,089 & 244 & 1 & 436 \\
$2009-2010$ & 48,268 & 822 & 12 & 688 \\
\hline
\end{tabular}

Source: Authors' calculations utilizing the German subsidy catalogue ("Förderkatalog")

Table 2 Network statistics

\begin{tabular}{llll}
\hline Year & Density & Avg. Degree & No of ties \\
\hline 2007 & 0.004 & 1.18 & 187 \\
2008 & 0.009 & 2.76 & 437 \\
2009 & 0.014 & 4.30 & 680 \\
2010 & 0.030 & 9.43 & 1490 \\
\hline
\end{tabular}

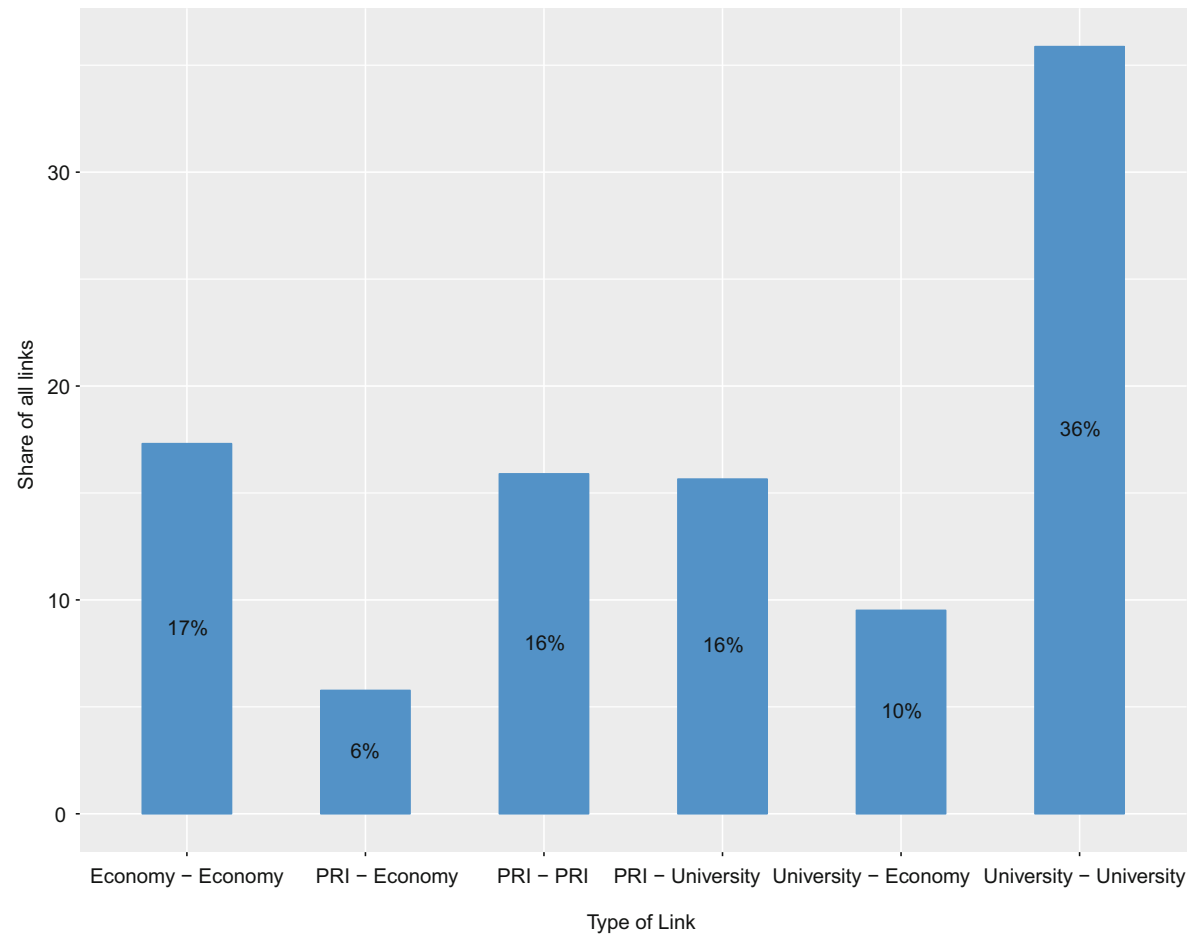

Fig. 3 Share of link types (own calculation based on German subsidy catalogue ("Förderkatalog"))

wards basic research, which tends to be very costly and complex with uncertain returns making public research facilities a necessity. However, knowledge diffusion between the private and public sphere takes place as about $10 \%$ of all links connect firms and universities. Given that just $6 \%$ of all links are established by joint projects between public research institutes (PRI) and firms, it implies that univer- 
sities are more important for knowledge diffusion into the private economy than public research institutes.

\subsection{Empirical variables}

\subsubsection{Actor level variable}

The most important variable at the actor level shows whether an organization is a university or not. The corresponding information is given in the database. In this paper, we combine public and private universities and technical colleges ("Fachhochschulen"). While the two types of organizations differ in some dimensions (Beise and Stahl 1999), their similarities preponderate in the context of the paper. The variable UNIVERSITY takes a value of 1 if an actor is a university or technical colleague and zero otherwise. Distinguished from that are public research institutes (PRI). The dummy variable RESEARCH summarizes a variety of state or publicly established research organizations like the Frauenhofer-, Max Planck- or Helmholtz institutes and associations (e.g. German Centre for Aviation and Space Travel). Those organizations that are not universities or research organizations are primarily firms and miscellaneous organizations. They serve as the reference group to identify the effect of UNIVERSITY and RESEARCH.

Fig. 4 shows the share of subsidies attributed to the different types of organizations for four consecutive years. The figure indicates the share of organizations belonging to the group of economic (firms) and public research institutes are alternating between all four years. While during 2007 economic organizations dominate in terms of being recipients of funding, the share is decreasing in the following years. Private research organizations account for around $30 \%$ of all shares during all years except for a decline in 2009. Apart from the first year, universities are the main recipient of joint $R \& D$ funding, highlighting their central role in the subsidized biotechnological R\&D network in Germany. The importance of universities as a recipient of public funding for joint $R \& D$ is further underlined by their rank in terms of project participation. Universities dominate the top 10 spots (see Table 3).

In addition to the organizational type, we also consider variance in organizations' size. The size variable (EMPLOYEES) captures the number of organization employees. For computational reasons, we do not use the number of employees directly but categorize the numbers according to the EU's definition of small and medium sized enterprises. The number of employees is rescaled to the categorical variable EMPLOYEES with the following categories: 1-9 employees (1), 10-49 employees (2), 50-249 employees (3), and more than 249 employees (4).

The third variable on the actor level is organizational experience. The variable captures if the respective organization was involved in any subsidized R\&D projects before the analysed time frame. Hence organizations experience is coded as a binary variable with 1 if they participated in earlier subsidized R\&D projects and 0 otherwise. 


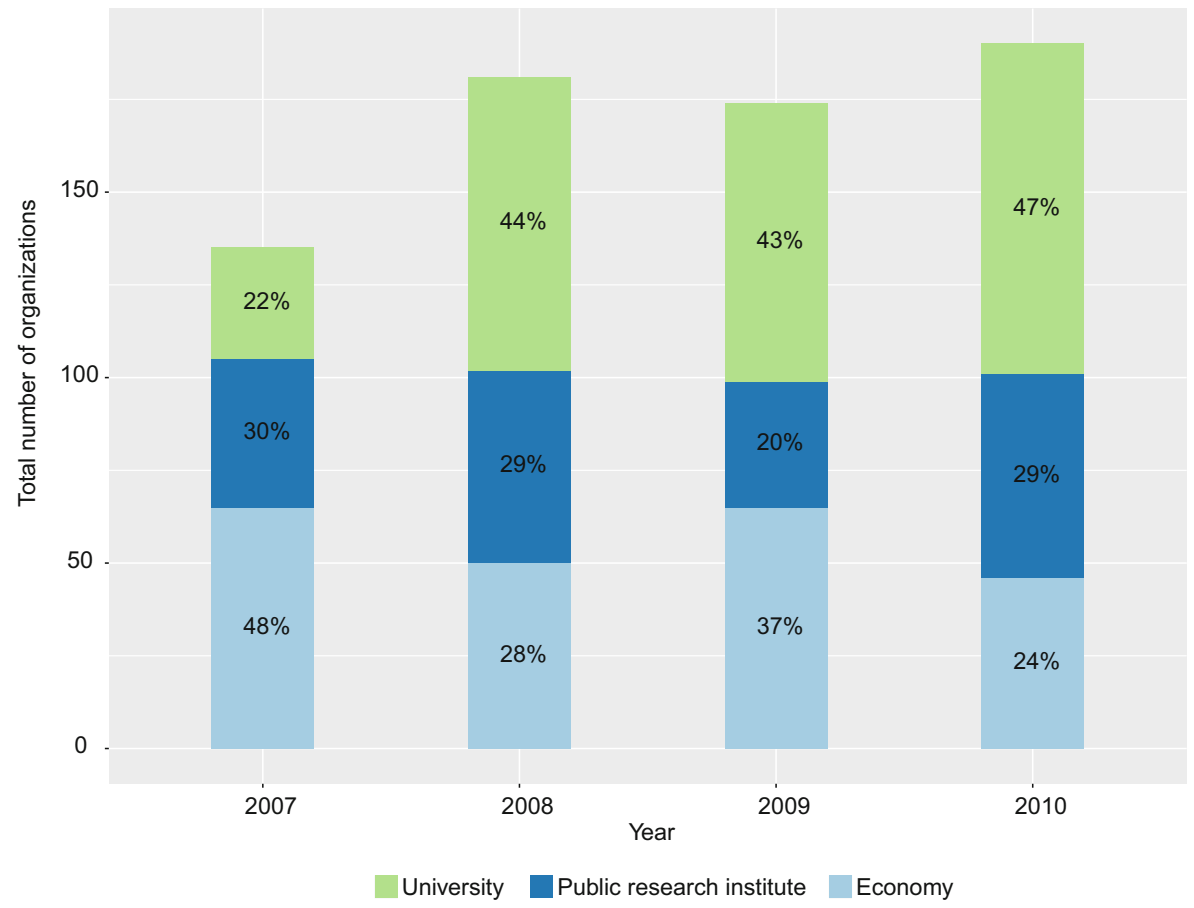

Fig. 4 Subsidies per organizational type (own calculation based on German subsidy catalogue ("Förderkatalog"))

Table 3 Top ten subsidy receiving organizations

\begin{tabular}{llll}
\hline Recipient Name & Region & Type & Projects \\
\hline Leibniz-Institut (IPK) & Salzlandkreis & Research & 22 \\
Christian-Albrechts-Universitaet & Kiel & University & 20 \\
Technische Universitaet Muenchen & Munich & University & 16 \\
Max-Planck-Gesellschaft (MPG) & Potsdam Mittelmark & Research & 15 \\
Georg-August-Universitaet & Goettingen & University & 14 \\
Rheinische Friedrich-Wilhelms-Universitaet & Bonn & University & 13 \\
Universitaet Hohenheim & Hohenheim & University & 12 \\
KWS Saat AG & Northeim & Economy & 12 \\
Universitaet Bielefeld & Bielefeld & University & 10 \\
Max-Planck-Gesellschaft (MPG) & Cologne & Research & 9 \\
\hline
\end{tabular}

Source: Authors' calculations utilizing the German subsidy catalogue ("Förderkatalog")

\subsubsection{Dyad level variables}

The first variable at the dyad level is institutional proximity (INST.PROX). Organizations share institutional proximity when they belong to the same type of institutional framework. As explained above, the database differentiates between universities, public research institutes, firms, and miscellaneous organizations. We 
construct a relational variable that takes a value of 1 if two organizations share the same institutional type and 0 otherwise.

Geographical proximity (GEOG.PROX) measures the spatial distance between two organizations based on their locations' latitude and longitude coordinates given in the data. Similar to Boschma et al. (2011), we take the natural log of the difference between the maximum distance found between any pair of organizations in the data and the individual dyadic distance of the focal pair of organizations. The result ranges between 0 and 6.44 , whereby 0 indicates the maximal and 6.44 the minimal distance.

Alternatively, to capture the importance of shared regional context, embeddedness into the same regional institutional innovation system and the advantages of geographical proximity, we construct the variable (SAME.NUTS). It obtains a value of one if two organizations are located within the same region and zero otherwise. A comparison of the two variables allows the investigation of the relative relevance of the regional context (SAME.NUTS) in contrast to "pure" spatial distance (GEOG.PROX).

Organizational proximity (ORG.PROX) is approximated by differentiating between executing and receiving organizations. As mentioned above, the subsidies database includes information on the organization receiving the grant and the organization actually conducting the research. In line with Broekel and Graf (2012), two organizations are argued to be part of the same mother organization when they share the name of the receiving organization and, hence, are characterized by organizational proximity. The variable ORG.PROX obtains a value of 1 if two organizations have the same mother organization and 0 if otherwise.

In order to account for cognitive proximity (COG.PROX), a more complex approach is needed. Following Broekel and Boschma (2012), we estimate cognitive proximity between organizations based on their sector membership given in the subsidies data. The data includes information on two-digit NACE codes for all subsidized organizations. In the case of universities, universities of applied science, and some research organizations three-digit NACE codes are available.

Based on this information, we construct a measure of technological similarity (cognitive proximity) for each pair of sectors included in the data. As each organization is assigned to a single sector, the measure can then be applied to describe inter-organizational technological similarity. For the construction, we follow the approach of Broekel and Brachert (2015). In a first step, we count the co-occurrence of six-digit research areas ("Leistungsplansystematik") as reported on each individual project ${ }^{4}$ acquired by two sectors' organizations in the preceding 10 years. The idea behind it is that the more frequently two sectors are subsidized through the same research areas (six-digit "Leistungsplansystematik") scheme, the more likely they are active in the same technologies. Hence, the greater their technological overlap, the smaller is their technological distance. The precise estimation is done in accordance with Teece et al. (1994) and Bryce and Winter (2009). The number of sixdigit area codes' co-occurrences on projects acquired by two sectors' organizations

\footnotetext{
4 As joint projects might be formed on the basis of resource complementarity and not similarity. We therefore exclude joint projects at this stage.
} 
( $i$ and $j$ ) is denoted as $J i j . J i j$ will naturally increase with the number of acquired subsidized projects. It is therefore compared to the number of co-occurrences that can be expected if projects are randomly assigned across all sectors' organizations. $K$ is the number of six-digit research areas and $n i$ represents the total number of individual projects organizations of sector $i$ are active in. $n j$ is the corresponding number for sector $j$. The expected number of projects in the same technological class acquired by sector $i$ and $j$ is (xij), which can be seen as a hypergeometric random variable whose mean and variance can be estimated as shown in Bryce and Winter (2009, p. 1575 f.). The sectors' size is approximated by the total number of acquired projects in this sector. The final index $\tau i j$ is then estimated as the standardized difference between the observed and expected numbers of co-occurrences. It refers to the "raw" number of co-occurrences of two sectors' organizations. In order to avoid size biases and allow for easier interpretation, it is standardized and divided by the maximal similarity score in the data. Negative values imply strong dissimilarity and hence their interpretation is the same as in the case of zero values. They are set to zero, implying that the final similarity index COX.PROX ranges between 0 and 1 with values close to one indicating maximal technological similarity.

We approximate social proximity by two organizations' collaboration history. The underlying assumption is that organizations have a distinct staff running R\&D projects. Hence, two organizations share social proximity (SOC.PROX) if both jointly participated in at least one subsidized $R \& D$ project in the 10 years prior to the investigated time period. The variable SOC.PROX is 1 if that is the case and zero otherwise.

To gain insights about potential knowledge diffusion from universities across institutional boarders, we define the two variables UNI.FIRM and UNI.PRI. UNI.FIRM takes the value of 1 in case of a university collaborating with a firm and 0 otherwise. Similarly, UNI.PRI. takes the value of 1 when a link is established between a university and a public research institute and 0 otherwise.

Finally, we add four interaction terms. UNIVERSITY*EXPERIENCE and UNIVERISTY*EMPLOYEES are included for testing the influence of the two actor level characteristics (experience and number of employees) on the probability of universities establishing links. UNI.FIRM*GEO.PROX and UNI.PRI*GEO.PROX are interaction terms between two dyad level variables and approximate the effect of geographical distance on specific types of university links.

The Siena model is estimated using the 7 dyadic variables approximating the different types of proximity, 3 node level variables capturing organization type (UNIVERSITY) and their size (EMPLOYEES), as well as organization experience (EXPERIENCE). In addition, we consider two network structural effects, density and preferential attachment as well as four interaction terms. The model estimates the year-to-year evolution of the network for the time period 2007-2010.

\section{Empirical results}

The results of the analysis for the biotechnology network in Germany between 2007 and 2010 are presented in Table 4. The estimation of parameters is based on repeated 
Table 4 RSiena results: Parameter estimates and their standard errors

\begin{tabular}{lll}
\hline & $2007-2010(n=316)$ & \\
\hline Rate parameters & & \\
RateParameter 1 & $1.766^{* * *}$ & 0.110 \\
RateParameter 2 & $1.647^{* * *}$ & 0.105 \\
RateParameter 3 & $5.045^{* * *}$ & 0.177 \\
Network structural factors & & \\
DEGREE.DENS & $-0.480^{* * *}$ & 0.127 \\
PREF.ATTACH & $0.075^{* * *}$ & 0.004 \\
Dyad-level factors & & \\
GEO.PROX & $-0.057^{* *}$ & 0.023 \\
INST.PROX & 0.074 & 0.056 \\
ORG.PROX & -0.067 & 0.387 \\
COG.PROX & $0.472^{* * *}$ & 0.059 \\
SOC.PROX & $-0.912^{* * *}$ & 0.353 \\
UNI.FIRMS & 0.067 & 0.076 \\
UNI.PRIS & -0.110 & 0.077 \\
Node-level factors & & \\
UNIVERSITY & $0.200^{* * *}$ & 0.099 \\
EMPLOYEES & $0.181^{* * *}$ & 0.043 \\
EXPERIENCE & 0.068 & 0.067 \\
Interaction terms & & \\
UNIVERSITY*EXPERIENCE & $1.113^{* * *}$ & 0.169 \\
UNIVERSITY*EMPLOYEES & $0.503^{* * *}$ & 0.137 \\
UNI.FIRMS*GEO.PROX & $0.105^{*}$ & 0.058 \\
UNI.PRIS*GEO.PROX & -0.027 & 0.055 \\
\hline Refers a & $* * 0.01$ &
\end{tabular}

* Refers to a significance level of 0.1 , ** 0.05 , and *** 0.01

Source: Authors' calculations utilizing the German subsidy catalogue ("Förderkatalog")

simulations to obtain a reliable (approximate) simulation of the observed network. The model was calculated 3 times with only negligible variation in the resulting parameter values. The computation includes simulation with 3000 repeated runs. Moreover, a convergence check for the estimation algorithm's convergence are the t-ratios. The t-ratio for convergence should be smaller than 0.1 in absolute value to indicate sufficiently fitted parameters (see Ripley et al. 2016).

The first part of Table 4 presents the estimated parameter values of the rate function. The rate function indicates the expected rate of change between the years for an actor and can be interpreted as the upper limit of expected changes.

The second part of the table shows the estimates for the structural network, dyad, and node level factors for their impact on link creation. As expected, DEGREE.DENS obtains a negative coefficient, which suggest organizations with many links are less likely to form new links. While this finding is frequently observed in the literature, such a straightforward interpretation is not possible in the context of this paper. Naturally, the variable DEGREE.DENS correlates strongly positively with the number of collaborative R\&D projects organizations are involved in because the more projects organizations acquire, the more likely they are to collaborate with 
new partners. Due to the correlation's magnitude, we cannot isolate the effect of project acquisition from that of network embeddedness. In other words, we cannot distinguish if organizations with many joint $R \& D$ projects are less likely to acquire new projects, or if organizations well embedded into the network do not strengthen this embeddedness any further. As these are quite distinct arguments, we refrain from this variable's interpretation. However, it is important to note that the variable DEGREE.DENS (through its correlation with the number of projects) controls for any project acquisition related effect implying that this issue is of less concern when interpreting the other variables.

The parameter of the structural network effect, preferential attachment (PREF. ATTACH), is significant and positive for the analysed time period. Thus, organizations involved in many subsidized R\&D collaboration are attractive collaboration partners for future collaboration. This may be due to their experience in collaboration, their past success in acquiring joint grants, and their access to knowledge in and about the network. In particular, the latter can be an advantage for new entrants into the network, as they can leverage the well-embedded collaboration partner to learn about future partners. Note, however, that this effect is different from that of DEGREE.DENS, as PREF.ATTACH captures the partner choice of new nodes entering the network.

Cognitive proximity (COG.PROX) is characterized by a significantly positive parameter. Overlap in technological knowledge bases stimulates the emergence of subsidized R\&D collaboration, which is in line with the proximity theory and adds to findings for unsubsidized R\&D collaboration (Cantner and Meder 2007; Broekel and Boschma 2012). Note that this finding relates to the intra-industrial knowledge network of a single industry. Hence, even within a relatively narrowly defined industry, such as biotechnology, cognitive proximity is of relevance. Hence, efficient collaboration seems to require a relatively large technological overlap.

The parameter for social proximity SOC.PROX gains a negative significant parameter. It means that organizations do not engage in repeated collaboration with the same partners. While it contrasts with the predictions of the proximity theory, it might be related to the underlying R\&D policies. Establishing new collaboration and bringing together new partners is one of the main arguments for the subsidization of joint R\&D in general. Repetitive collaboration between the same set of partners might therefore have lower chances to be approved for consecutive public funding.

The variable SAME.NUTS, which approximates if two organization are located within the same region, remains insignificant and interferes with the effect of GEO.PROX. For reasons of model convergence, we drop SAME.NUTS from the estimations. The parameter of geographical proximity (GEO.PROX) obtains a significantly negative parameter. Thus, "pure" geographic distance is of relevance here and not the regional context. Interestingly, the negative coefficient of GEO.PROX indicates geographic proximity hindering the chances of joint participation in subsidized R\&D projects and thereby the establishment of links. This finding seems to contradict the proximity theory and the results of most empirical studies (Ter Wal 2013; Balland 2012). However, the industry is dominated by basic research, which amongst others, shows in a dominance of network relations between universities (see Fig. 3). Universities are rarely in geographic proximity to each other, implying that 
these links span relatively large geographic distances. This argument is supported by the significantly positive coefficient of UNI.FIRMS*GEO.PROX, which will be discussed later.

While we cannot entirely rule out an effect of underlying policy designs that may also cause this finding, such an effect seems unlikely because in the available policy descriptions, there were no indications of explicit support of inter-regional collaboration documented.

We find no significant coefficient for INST.PROX. The outcome suggests that the intuitional framework in which institutions are embedded does not foster collaboration. Most likely, other variables capture some of its effects. That is, as we define a number of variables focused on the behaviour of universities (e. g., UNI.FIRMS, UNI.PRIS, and UNIVERSITY) and universities represent a large part of this industry, there are probably too few cases that are uniquely captured by INST.PROX.

Organizational proximity (ORG.PROX) does not gain a significant parameter. While proximity theory would predict a positive effect, indicating that belonging to the same organizational group (e.g. firm, university) makes collaboration more likely, as it is associated to higher levels of trust and thereby less at risk of opportunistic behaviour, we cannot find any effect of organizational proximity in the analysed network.

At the node level, we consider EMPLOYEES in order to control for organizations heterogeneity in size. This variable's parameter becomes significantly positive, indicating that large organizations are more prone to establish new links. This fits with the idea that larger organizations can mobilize more resources for participation in R\&D projects. Since many policy support programs aim at supporting collaboration with and among small and medium sized businesses, we might have expected this variable to remain insignificant. Our results indicate that such programs seem to be of little relevance in the biotechnology industry.

The actor variable EXPERIENCE shows no significance. It is assumed that organizations build up experience over time which in turn helps them to apply, conduct, and finish subsidized R\&D projects and makes them more attractive to future collaboration partners. However, for organizations in the biotechnology industry, experience does not seem to have any effect on the likelihood of participation in a subsidized collaboration project in the analysed period.

In the context of the present paper, we are especially interested in the variable UNIVERSITY. It gains significance with a positive parameter. This indicates that universities are much more active collaborators in comparison to firms and research organizations. This meets our expectations and underlines the crucial role universities play for knowledge generation and diffusion in the biotechnology industry (see also Niosi and Banik 2005). Moreover, it suggests that subsidies for joint R\&D succeed in stimulating the collaborative activities of universities in the field of biotechnology. The positively significant coefficient of the interaction term UNIVERSITY*EXPERIENCE suggests that universities' prior experience with collaborative $R \& D$ increases their probability to (re-)engage in joint projects in the future. Most likely, their experience helps them to write good proposals that are more likely to get funded (see, e. g., Barajas and Huergo 2010). The interaction term UNIVERSITY*EMPLOYEES also obtains a significantly positive coefficient, suggesting that 
larger universities are more likely to engage in collaboration. This meets our expectations, as writing project proposals and engaging in joint $R \& D$ projects requires human resources and consequently, more employees, allowing being active in more or or bigger projects (see also on this Marın and Siotis 2008).

The other two interaction terms are similarly interesting. The coefficient of the interaction term UNIVERSITY.FIRM*GEO.PROX becomes positively significant, implying that linkages between universities and firms tend to be of shorter geographic distance than other types of links by universities. The insignificant coefficient of UNIVERSITY.PRI*GEO.PROX underlines that this exclusively applies to university-firm relations.

Accordingly, universities contribute to knowledge diffusion by linking with other organizations (many of which are universities too) at greater distance (negative coefficient of GEO.PROX) and simultaneously connecting with the local economy. Our study thereby delivers further evidence for universities being important regional gatekeepers. That is, characterized by larger resources and stronger incentives to collaborate (inter-regionally), they connect local firms to inter-regional knowledge networks. While this behaviour has been observed in unsubsidized networks (see, e. g., Graf and Henning 2009), our analysis confirms this for networks of subsidized R\&D collaboration. Consequently, subsidies for joint R\&D projects help universities in acting as regional gatekeepers, which is particularly crucial for small and medium firms that frequently lack resources to connect to inter-regional knowledge flows on their own (Giuliani and Bell 2005).

\section{Conclusion}

The presented study investigates the evolution of a network that emerged from subsidized R\&D collaboration in the German biotechnology industry. To this end we estimated a Stochastic Actor Oriented Model based on a network emerging from the subsidization of joint R\&D projects by the German federal government between 2007 and 2010. Besides network structural factors such as preferential attachment, the study considered a wide range of proximities (social, cognitive, institutional, geographical, organizational) that may impact the network's evolution. Most importantly, we also differentiated between research institutes, firms and universities participating in the network.

Our empirical findings confirm that cognitive proximity enhances the probability of subsidized R\&D collaboration. The results furthermore indicate that entrants into the industry tend to establish their first collaboration with organizations holding central positions in the network, which corresponds to a preferential attachment process. In contrast to these findings, which mirror those for unsubsidized collaboration, we identified a number of peculiarities, which we attribute to the network evolving on the basis of subsidies for joint processes. Notably, social and geographic distance are found to hinder R\&D collaboration, which contrasts with predictions of the proximity theory. In the case of social, we interpret this as a desired feature of the underlying policy design that, in order to stimulate economy-wide knowledge diffusion, penalizes repeated interaction between the same organizations. The neg- 
ative effect of geographic proximity is most likely specific to the studied network, which is dominated by collaboration among universities. These are rarely located in geographic proximity. Indeed, we geographic proximity to be of positive relevance for collaboration between universities and firms. By linking local firms to geographically distant knowledge sources, the study confirms universities acting as regional gatekeepers in the context of subsidized R\&D collaboration. Accordingly, projectbased R\&D subsidies help universities to play this role and thereby stimulate local and inter-regional knowledge diffusion.

With the current research design we cannot differentiate between whether universities are more active in collaboration due to their higher propensity of acquiring $\mathrm{R} \& \mathrm{D}$ subsidies or due to a higher likelihood of engaging in collaborative research. However, we want to highlight two points supporting our interpretation. First, R\&D subsidization undergoes a review process beforehand to determine the usefulness and novelty of potential projects. Usually, acceptance rates are below $10 \%$ in these programs. Therefore, even if universities seek to maximize their R\&D subsidies, they will have to back it up with rigorous and competitive research. Hence, we are confident that we did not simply pick up some kind of third-party fund inflation at the level of universities. Second, as the network model looks at the evolution of the network between subsequent points in time, a positive coefficient of UNIVERSITY implies that universities are more actively collaborating in later periods than in earlier ones, except for the period 2009 in which we see a decreasing engagement of universities in R\&D subsidies in biotechnology (see Fig. 4). Although it could be argued that some of the effect simply reflects a generally higher engagement of universities in R\&D subsidization, we are confident that the prior arguments show other valid reasons why universities may also be prone to collaborate at a higher rate within the subsidized biotechnology R\&D network.

Our research shows that the policy of subsidizing joint R\&D seems to be successful in fuelling potentially fruitful collaboration. This is in line with previous research showing that R\&D subsidies for joint projects may (under certain conditions) lead to increases in biotechnology firms' innovation success (Fornahl et al. 2011). This paper adds to this literature by exploring this choice of partners in subsidized joint $\mathrm{R} \& \mathrm{D}$ projects from a network perspective. Moreover, with a focus on the biotechnology industry the present study extends our understanding about the evolution of a subsidized cooperation network in the context of an analytical knowledge driven industry. In contrast to previous studies on the evolution of subsidized networks, the present paper illuminates the relevance of universities for the development of such networks. It particularly confirms the importance of universities in linking local firms to inter-regional knowledge sources. However, the present study does not test for any effects on measurable outcomes resulting from this (e.g. patents or publications). This clearly calls for future research. Nevertheless, the paper presents a research design that is a first step towards an evaluation of R\&D policy measures designed to stimulate inter-organizational knowledge diffusion.

An important question which we cannot answer within the scope of this paper is that of the development of the biotechnology network over the last six years. While biotechnology in Germany is still considered one of the central pillars of the research and scientific landscape, the availability of detailed data restricts the study 
to the given time frame. Despite this limitation, the study covers a period of high growth in terms of participants and projects up until 2010. It therefore gives insights about a rapidly growing network emerged from the support of public funding. The analysed parameter on the actor, dyadic, and network level reflect the driving forces which shape emerging biotechnology in an early stage of the industry life cycle.

Future research might therefore not only consider a comparison of different industries and their underlying R\&D programs to further validate our results, but also emphasize the life cycle of the analysed industry. We still know little about how R\&D policy impacts knowledge networks and to what extent industry specificities may play a role. It might also be worthwhile to analyse actors and their characteristics that hold central positions in such networks, as these are essential for network wide knowledge diffusion. Variance in the responses to R\&D subsidization programs are likely to exist when collaboration is mandatory for receiving grants.

In general, while our research contributes to the understanding of the development and drivers of subsidized joint R\&D networks on a macro scale, there is up to now only little research of impacts within organizations. This particularly includes expanding the focus from pure input and output additionalities of R\&D subsidies to behavioural additionalities, which might be of similar or even greater relevance in this context as, presumably, no participating organization is left unaffected by external R\&D subsidies.

Open Access This article is distributed under the terms of the Creative Commons Attribution 4.0 International License (http://creativecommons.org/licenses/by/4.0/), which permits unrestricted use, distribution, and reproduction in any medium, provided you give appropriate credit to the original author(s) and the source, provide a link to the Creative Commons license, and indicate if changes were made.

\section{References}

Asheim BT, Coenen L (2005) Knowledge bases and regional innovation systems: Comparing nordic clusters. Res Policy 34(8):1173-1190

Asheim BT, Gertler MS (2004) Regional innovation systems and the geographical foundations of innovation. In: Fagerberg J, Mowery DC, Nelson RR (eds) Oxford handbook of innovation. Oxford University Press, Oxford, UK

Balland P (2012) Proximity and the evolution of collaboration networks: Evidence from research and development projects within the Global Navigation Satellite System (GNSS) industry. Reg Stud 46(6):741-756

Barab'asi A-L, Albert R (1999) Emergence of scaling in random networks. Science 286(5439):509-512

Barajas A, Huergo E (2010) International R\&D cooperation within the EU framework programme: Empirical evidence for Spanish firms. Econ Innov New Technol 19(1):87-111

Beise M, Stahl H (1999) Public research and industrial innovations in Germany. Res Policy 28(4):397-422

Blind K, Grupp H (1999) Interdependencies between the science and technology infrastructure and innovation activities in German regions: Empirical findings and policy consequences. Res Policy 28(5):451-468

BMBF (2006) Bericht zur technologischen Leistungsfähigkeit Deutschlands 2006

Boschma R (2005) Proximity and innovation: A critical assessment. Reg Stud 39(1):61-74

Boschma R, Frenken K (2010) The spatial evolution of innovation networks. A proximity perspective. In: Boschma RA, Martin R (eds) The handbook of evolutionary economic geography. Edward Elgar, Cheltenham, pp 120-135

Boschma R, Balland P, Kogler D (2011) A relational approach to knowledge spillovers in biotech. Network structures as drivers of inter-organizational citation patterns. Pap Evol Econ Geogr 11:20

Breschi S, Cusmano L (2004) Unveiling the texture of a European research area: Emergence of oligarchic networks under EU framework programmes. Int J Technol 27(8):747-772 
Broekel T, Boschma R (2011) The cognitive and geographical composition of ego-networks of firms-and how they impact on their innovation performance. Pap Evol Econ Geogr 11:18

Broekel T, Boschma R (2012) Knowledge networks in the Dutch aviation industry: The proximity paradox. J Econ Geogr 12(2):409-433

Broekel T, Brachert M (2015) The structure and evolution of inter-sectoral technological complementarity in R\&D in Germany from 1990 to 2011. J Evol Econ 25(4):755-785

Broekel T, Graf H (2012) Public research intensity and the structure of German R\&D networks: A comparison of 10 technologies. Econ Innov New Technol 21(4):345-372

Broekel T, Hartog M (2013a) Determinants of cross-regional R\&D collaboration networks: An application of exponential random graph models. In: Scherngell T (ed) The geography of networks and R\&D. Springer, Switzerland, pp 49-70

Broekel T, Hartog M (2013b) Explaining the structure of inter- organizational networks using exponential random graph models. Ind Innov 20(3):277-295

Broekel T, Balland P-A, Burger M, van Oort F (2014) Modeling knowledge networks in economic geography: A discussion of four methods. Ann Reg Sci 53(2):423-452. https://doi.org/10.1007/s00168014-0616-2

Bryce DJ, Winter SG (2009) A general Interindustry relatedness index. Manage Sci 55(9):1570-1585

Buchmann T, Pyka A (2014) The evolution of innovation networks: The case of a publicly funded German automotive network. Econ Innov New Technol 24(1-2):1-26

Camagni R (1991) Local "milieu", uncertainty and innovation networks: Towards a new dynamic theory of economic space. In: Camagni R (ed) Innovation networks: Spatial perspectives. Belhaven Stress, London, UK and New York, USA, pp 121-142

Cantner U, Meder A (2007) Technological proximity and the choice of cooperation partners. J Econ Interact Coord 2(1):45-65

Cassi L, Morrison A, Wal TALJ (2012) The evolution of trade and scientific collaboration networks in the global wine sector: A longitudinal study using network analysis. Econ Geogr 88(3):311-334

Cockburn I, Henderson R (1997) Public-private interaction and the productivity of pharmaceutical research. National Bureau of Economics Research working papers, vol. 6018.

Cohen WM, Levinthal DA (1990) Absorptive capacity: A new perspective on learning and innovation. Adm Sci Q 35(1):128-152

Dohse D (2000) Technology policy and the regions-The case of the BioRegio contest. Res Policy 29:1111-1133

Feldman MP, Florida R (1994) The geographic sources of innovation: Technological infrastructure and product innovation in the United States. Ann Assoc Am Geogr 84(2):210-229

Fontana R, Geuna A, Matt M (2006) Factors affecting university-industry R\&D projects: The importance of searching, screening and signalling. Res Policy 35(2):309-323

Fornahl D, Broekel T, Boschma RA (2011) What drives patent performance of German biotech firms? The impact of R\&D subsidies, knowledge networks and their location. Pap Reg Sci 90(2):395-418

Fritsch M, Lukas R (2001) Who cooperates on R\&D? Res Policy 30(2):297-312

Fritsch M, Slavtchev V (2007) Universities and innovation in space. Ind Innov 14(2):201-218

Gibbons M (1994) The new production of knowledge: The dynamics of science and research in contemporary societies. SAGE, Thousand Oaks. https://doi.org/10.4135/9781446221853

Giuliani E, Bell M (2005) The micro-determinants of meso-level learning and innovation: Evidence from a Chilean wine cluster. Res Policy 34(1):47-68

Graf H, Henning T (2009) Public research in regional networks of innovators: A comparative study of four East German regions. Reg Stud 43(10):1349-1368

Grant R (1996) Toward a knowledge-based theory of the firm. Strateg Manag J 17:109-122

Hagedoorn J (1993) Understanding the rationale of strategic technology partnering: Organizational modes of cooperation and sectoral differences. Strateg Manag J 14(5):371-385

Hagedoorn J (2002) Inter-firm R\&D partnerships: An overview of major trends and patterns since 1960. Res Policy 31(4):477-492

Jaffe AB (1989) Real effects of academic research. Am Econ Rev 79(5):957-970

Kesteloot K, Veugelers R (1995) Stable R\&D cooperation with spillover. J Econ Manag 4:651-672

Kogut B, Zander U (1992) Knowledge of the firm, combinative capabilities, and the replication of technology. Organ Sci 3(3):383-397

Lazarsfeld PF, Merton RK (1954) Friendship as social process: A substantive and methodological analysis. In: Freedom and control in modern society, vol 2, pp 18-66

Levitt B, March J (1988) Organizational learning. Annu Rev Sociol 14:319-340 
Mansfield E, Lee JY (1996) The modern university: Contributor to industrial innovation and recipient of industrial R\&D support. Res Policy 25(7):1047-1058

Marin PL, Siotis G (2008) Public policies towards research joint venture: Institutional design and participants' characteristics. Res Policy 37(6-7):1057-1065

Meyer-Krahmer F, Schmoch U (1998) Science-based technologies: University-industry interactions in four fields. Res Policy 27:835-851

Niosi J, Banik M (2005) The evolution and performance of biotechnology regional systems of innovation. Cambridge J Econ 29(3):343-357

Owen-Smith J, Riccaboni M, Pammolli F, Powell WW (2002) A comparison of U.S. and European university-industry relations in the life sciences. Manage Sci 48(1):24-43

Plum O, Hassink R (2011) Comparing knowledge networking in different knowledge bases in Germany. Pap Reg Sci 90(2):355-371

Powell WW, Koput KW, Smith-doerr L (1996a) Interorganizational collaboration and the locus of innovation: Networks of learning in biotechnology. Adm Sci Q 41(1):116-145

Powell WW, Koput KW, Smith-Doerr L, Walter W (1996b) Interorganizational collaboration and the locus of innovation: Networks of learning in biotechnology. Adm Sci Q 41(1):116-145

Powell WW, White DR, Koput KW, Smith OJ (2005a) Network dynamics and field evolution: The growth of Interorganizational collaboration in the life sciences. Am J Sociol 110(4):1132-1205

Powell WW, White DR, Koput KW, Owen-Smith J (2005b) Network dynamics and field evolution: The growth of interorganizational collaboration in the life sciences. Am J Sociol 110(4):1132-1205

Ripley R, Snijders T, Preciado P (2011) Manual for RSIENA. University of Oxford, Oxford

Ripley R, Snijders T, Preciado P (2016) Manual for RSIENA. University of Oxford, Department of Statistics, Oxford

Scherngell T, Barber MJ (2009) Spatial interaction modeling of cross-region R\&D collaboration. Empirical evidence from the 5th EU framework programme. Pap Reg Sci 88(3):531-546

Scherngell T, Barber MJ (2011) Distinct spatial characteristics of industrial and public research collaborations: Evidence from the fifth EU framework programme. Ann Reg Sci 46(2):247-266

Snijders TAB (1996) Stochastic actor-oriented dynamic network analysis, J Mathematical Sociol 21:149-172. https://doi.org/10.1080/0022250X.1996.9990178

Snijders T (2001) The Statistical Evaluation of Social Network Dynamics. Sociol Methodol 31(1):361-395

Snijders T, Van de Bunt GG, Steglich CE (2010) Introduction to stochastic actor-based models for network dynamics. Soc Networks 32(1):44-60

Soete B, Wurzel U, Drewllo H (2002) Innovationsnetzwerke in Ostdeutschland: Ein noch zu wenig genutztes Potential zur regionalen Humankapitalbildung. DIW Wochenber 16:251-256

Staehler T, Dohse D, Cooke P (2007) Evaluation der Fördermaßnahmen BioRegio und BioProfile. Technical report. Bundesministerium für Bildung und Forschung (BMBF), Berlin

Steglich C, Snijders T, Pearson M (2010) Dynamic networks and behavior: Separating selection from influence. Sociological 40(1):329-393

Teece DJ, Rumelt R, Dosi G, Winter S (1994) Understanding corporate coherence. J Econ Behav Organ 23(1): $1-30$

Ter Wal ALJ (2013) The dynamics of the inventor network in German biotechnology: Geographic proximity versus triadic closure. J Econ Geogr 8(1):1-6

Toole A (2012) The impact of public basic research on industrial innovation: Evidence from the pharmaceutical industry. Res Policy 41(1):1-12

Van de Bunt GG, Groenewegen P (2007) An actor-oriented dynamic network approach: The case of interorganizational network evolution. Organ Res Methods 10(3):463-482

Varas MLL (2007) Essays in social space: Applications to Chilean communities on inter-sector social linkages, social capital, and social justice. University of Illinois, Urbana-Champaign (Dissertation)

Zeller C (2001) Clustering biotech: A recipe for success? Spatial patterns of growth of biotechnology in Munich, Rhineland and Hamburg. Small Bus Econ 17(1-2):123-141

Zollo M, Reuer J, Singh H (2002) Interorganizational routines and performance in strategic alliances. Organ Sci 13(6):701-713. https://doi.org/10.1287/orsc.13.6.701.503 